\section{Psicanálise}

e memária

Antonio Sérgio

Mendonça

Analisando as mais representativas concepções não-freudianas de memória, desde a concepção psicológica de Henri Bergson (1896), o estudo detém-se na concepção freudiana esboçada desde o fim do século XIX. Reflete sobretudo sobre as duas principais consequências dessa última abordagem, representada por Lacan e pelos autores que renovaram a questão da cientificidade histórica para além da Ciência Lógica de Hegel e do materialismo histórico marxista.

abstract Analysing the most representative non-freudian conceptions of memory, the study reflects essentially on the approach represented by acan and the authors that renovated the question of historic scientificity. 


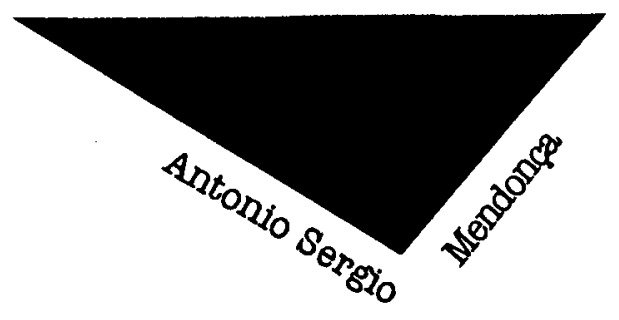

\title{
Psicanálise e memória
}

\author{
"Nem sempre sou igual no que digo e escrevo. \\ Mudo, mas não mudo muito. \\ A cor das flores... as flores \\ são cor de lembranca".
} (Fermando Pessoa - In... OGuardadorde Rebanhos)

Começaremos por abordar as concepgões não-freudianas de memória, freqüentemente pré-freudianas e, certamente, apenas as mais representativas.

Em 1896, Henri Bergson nos brinda, embora filósofo, com uma concepção psicológica de memória. Por esta ser imagética e relativa à percepção e ao tempo: denominava-se Durée. A par de sua própria importância, esta, de fato, deveu-se a uma nova e atribuída importância posterior e, mesmo esta permanência deveu-se à conexão, indébita para alguns, feita entre esta (sua) concepção de memória e o romance proustiano, já então "auratizado" também pela figura do Autor Fictício. Este efeito literário algo tardio, faz Marcel Proust dotar a visão bergsoniana da busca do pretérito perdido, pondo, para alguns, em suspensão, a perenidade desta perda. Data esta sua obra de 1913 até 1927. E nesta "busca do tempo perdido", Proust irá fundir mito, historicidade e imaginário romanesco. E a ser correta sua extensão com relação a Bergson ele a torna, com isto, contemporânea do pensamento

Antonio Sérgio Mendonça Lima é Professor Titular do Departamento de Comunicação Social da Uff, Doutorem Letras pela UFRJ. 
freudiano. No entanto, dialogante, contemporâneo e parcialmente recusado por Freud, que é, aliás, acusado de ter um gosto clássico em Literatura (Thomas Mann, Dostoiévski, Sófocles, com exceção talvez de Jensen) surge o Surrealismo de Breton e sua correspondente concepção de memória. No entanto, por sua vez, o Surrealismo, qual posteriormente fixou Jean Starobinski, sobressaíram-se os traços do Ocultismo de Myers, logo eles, que esperavam ver na "escrita automática" uma espécie de Ics "gramática arquetipal" (junguiana, de fato, portanto). Contudo, Freud não acatará a equivalência proposta por Breton entre a "escrita automática" e o Ics, preferindo vê-lo como análogo à lógica do processo primário. Em tempo, os surrealistas se queriam freudianos... O que, aliás, levou o Lacan dos anos 60 a dizê-lo uma "formação" do Ics, por ser "estruturado como uma linguagem", não obstante ter estabelecido uma equivalência, para tal, entre a sua "lógica do significante" a lógica do objeto a e a própria lógica freudiana do processo primário. Mas isto não o impediu de freqüentar e valorizar, ao contrário de Freud, os surrealistas, vendo neles e em Spinoza as bases de sua inicial teoria das psicoses. Do último importou a categoria de "paralelismo disjuntivo", e não de Breton, mas de Salvador Dali, incorporou o chamado "método paranóico", onde fundiu esta suposição de Freud com a imperatividade da "escrita automática". (Ao contrário de Dali), todavia, René Magritte, que fez a metáfora escópica do freudiano "Rochedo da Castração" no seu trabalho "Castelo dos.Pirineus", surrealista, provavelmente por razões desta ordem, paradoxalmente, abominará a Psicanálise. Mas, Dali e Magritte à parte, foi Breton, em Carnets, em tempo também contemporânen a Freud, que formulnu a idéia surrealista de memória em 1922, como "fruto único da imaginação criadora", sendo esta, é óbvio, desdobramente, a seu juízo, Ics, da "escrita automática".

Paralelamente a estes movimentos, também se supondo afetada por Freud, mas jamais tendo conseguido "incorporar" sua categoria de "pulsão de morte", conforme atesta o testemunho deste fracasso um Erich Fromm, e, embora vários autores digam-na, malgrado os equívocos conceituais de Adorno, e mesmo de Benjamin, um se contrapondoe outro pretendendo assimilar esta tendência freudo-marxista, será um Marcuse "made in USA", que tentará, a partir de sua categoria de "dessublimação repressiva", fundi-los, ou seja, fundir um Marx neo-hegeliano a um Freud 
pré-1920, portanto, biologista. Tudo isto foi feito em nome da crítica ao outrora companheiro da fase alemã (Fromm), último estertor teórico deste inicial discípulo de Heidegger. No entanto, são suas - de Adorno e Marcuse - as concepsões de memória que dialogam com Freud e com 0 pensamento pós-freudiano, apenas historiográfica, jamais conceitualmente. A dita Escola Neo-Hegeliana de Frankfurt, embora fosse a juízo de Phil Slater, no período Adorno/Horkheimer da fase alemã, a propriamente representante do predomínio do que Marcuse denominou de Marxismo Alemão, vinculado ao ideário da $3^{\mathrm{a}}$ Internacional, ainda que de tardia influência hegeliana, e fora, também, proponente de uma Teoria Crítica e Materialista da Sociedade, exposta no Instituto de Pesquisa Social e baseada no binômio: Alienação X Repressão, e, mesmo no exílio, com o concurso do próprio Marcuse, viesse a publicar na revista do Instituto de Pesquisa Social, a contribuição mais famosa de Walter Benjamin, foi assimilada como um tardio marxismo neo-hegeliano. Esta variante do marxismo, diferente, ainda a juizo do próprio Marcuse, do totalitário, também para Hannah Arendt, Marxismo Soviético, e, desdobrou-se como uma das vertentes, na concepção de Perry Anderson, do dito Marxismo Ocidental. Porém, malgrado tudo isto, em tempo contemporâneo ao de Freud (os anos 20/30) na Alemanha, Marcuse faz equivaler, para negar, a anistia (perdão) ao esquecimento. Exprime ali uma visão pedagógico-consciente de memória, com indisfarçáveis, ressentidas e inquisitoriais incursōes na fusão entre "injustiça" e reparação político-moral, sem dúvida contextualmente abalado pelos efeitos de perversidade da ascensão do nazismo. Age discursivamente como um "anjo vingador", aposta no princípio perverso-taliônico da "vendetta", a pretexto de equivaler justiça a linchamento moral. Eembora tal procedimento possa ser entendido como uma "justificável" "formação reativa" face aos, infelizmente, inevitáveis efeitos de perversidade daquela "barbárie", cria-se, ainda assim, a pretensão de que com tal procedimento ela venha a ser abolida para sempre e não, justa e possivelmente, reforçada. O sintagma: NUNCA MAIS, hoje vinculado à condenação da perversidade homicida da tortura, não a evita, não a impede, assim como não impediu a guerra $\mathrm{e}$ foi originado da esquerda inglesa no pós $\cdot 1^{\mathrm{a}}$ Guerra Mundial, como reação à chacina dos operários que morreram pelos nobres e pelos reis e chegou, até, a ter, ao contrário 
de Hitler, sempre um belicista, em Mussolini (aliado tenso dos reformistas) um líder socializante do pacifismo... Por isto, Marcuse insiste na psicótica memória do "trauma" ao dizer que "Oesquecimento seria o perdão do não-perdoável, e, neste caso, inscrever-se-ia a justiça”. E a isto, como desdobramento possível, acrescentar-se-á, na mesma linha de raciocínio, a concep̧̧ão adorniana, que é também afetada, como uma outra sua concepção de poeta enquanto porta-voz da utopia, pelos efeitos totalitários do nazismo alemão. Mantém a mesma linha de reparação político-moral marcusiana, ao que acrescenta uma visão terapêutica da memória. Nele ela é também um anti-esquecimento, e insiste na "incurável" lembrança permanente do "trauma", onde, a pretexto, também, de se criticar, no nível da Consciência, os efeitos da perversidade totalitária, condenamo-nos, paradoxalmente, de saída, a rememorá-los conjuntamente e para sempre. Supõe, por ingenuidade, que o traumático pode ser recalcado, quando ele é sempre foracluído, e que rememorá-lo não é obviamente mórbido e da ordem de um psicótico e permanente masoquismo erógeno, já que não os trata enquanto matéria Ics, conquanto a memória para Freud apenas registre alia a "indestrutibilidade do desejo". E como não há a possibilidade de se "controlar o Ics" por nenhum imaginário "superego" político-moralizante, natural ou não, tem-se como resultado prático disto a ilusão futura a dissimular o culto à perversidade, feito na forma (de lembrança) do que se dizia pretender para sempre combater e/ou banir. Não há "controle do imaginário" que se confunda com "retorno do recalcado", e desde o Kant com Sade de Lacan fica-nos óbvio, principalmente do ponto de vista da "câmara secreta" e da inferição de Real postulada pulsionalmente pela voz, e "bergmianamente" em Gritose Sussurros, que o ponto de vista do carrasco não se distingue do da vítima, ou seja não se pode diferenciar o gozodo carrasco com o gozocom o carrasco, vide o filme PORTEIRO DA NOITE. Para manter tais equívocos ainda hoje em voga diz-nos Adorno: " $A$ Memória deve ser a lembrança e não o esquecimento do traumático, para que ele não se repita". Ora, destas concepções, agora agrupadas, restanos a expansão do masoquismo sob as formas psicótica e/ou melancólica, vigentes nos desgraçados anos 30 e nos não menos felizes anos $60 / 70 \mathrm{e}$ por que não até hoje? $\mathrm{E}$ a única forma de mantê-la em vigor não é a morte e sim a paralisação da História, por isto, para alguns, 1968 ainda não 
acabou... Mas, distanciando-se desta "para sempre vendetta" e optando, de fato, pelos "excluídos", Walter Benjamin irá articular a memória à ironia, à tradição da estética romântica alemã, à corrosão, à história dos vencidos. E se não fala nisto, abre campo para a atual concep̧̧ão dos "senhores da memória", embora os circunscreva, então, aos "vencidos", ao resto, ao fragmento.

Mas, parece que enfim chegamos ao momento de expor a concepcãa freudiana de memória que foi esboçada desde o fim do século XIX, principalmente nas explícitas referências ao caráter mnêmico da representação de palavras na Traumdeutung freudiana (1900). De lá pode-se inferir, ao contrário da linha de raciocício frankfurtiano, que a memória, por ser articulada à indestrutibilidade do Desejo, refere-se à fantasia Ics $(\$ \uplus D)$ e é passivel de abordagem, no nível transferencial do Desejo do Psicanalista, do lado do esquecimento e da construção. Isto nos leva, como na leitura freudiana da Gradiva de W. Jensen, à sua reconstituição arqueológica, e, portanto, nos termos já de Lacan, se organizaria conforme a lógica do fantasma, isto é, a do objeto a . Ali, portanto, de forma não-traumática, já que o liame social deste é sempre produtor de questão psicótica, é produto da opção freudiana pelo Édipo e pela Castração e, nos termos lacaneanos, pelo significante. Neles se diz: "só o que pode ser esquecido, deve ser lembrado", já que há recalque, o seu retorno é o único que houve e, nos termos de Lacan, o Real volta sempre no mesmo lugar.

Pode-se, hoje, observar duas das principais conseqüências de Freud que estão representadas por Lacan e pelos autores que, entre outros, renovaram, a partir do caráter cotidiano, ficcional e intra-subjetivo do rela to e da apreciação e/ou escolha do documental, a questão da cientificidade histórica, sem dúvida, para além da expressiva Ciência Lógica de Hegel e do materialismo histórico marxista. Em L'Etourdit Lacan oferece disso uma nova versão, produzida desde a escuta, à freudiana concepção de memória, pois se só o que pode ser esquecidoé que deve ser lembrado, é porque se trata de um "dito que é esquecido no que se ouve". Masé na incursão histórica que a similitude com a concepção freudiana é articulada por três pensadores, a saber:

a) Jacques le Goff, pois, ao dizer que o esquecimento é o verdadeiro silêncio da história, inverte a lide frankfurtiana e a politiza ao afirmá- 
la como fruto e/ou prerrogativa dos "senhores da memória";

b) este tipo de articulação entre memória e poder é mantido (Cf. Diálogos sobre a Nova História) por Georges Duby ao dizer: "a memória importa pelo que esquece";

c) masé, sobretudo, David Lowenthal (Cf.The past is a foreign country) o que se aproxima de fato do dito freudiano ao afirmar "só é possível lembrar porque é permitido esquecer", embora, lacaneanamente 0 oposto seja mais rigoroso. Deste modo, para esta última concepção "só é possivel esquecer porque é permitido lembrar", ela não só parece dar conta do caráter Ics da memória, mas também nos adverte sobre os "senhores" da História escrita, sobre os manipuladores ideológicos da memória, que são os produtores de sua domesticação. Se a memória faz enlace coletivo, liame social e possui natureza Ics, não se trata de "escolhê-la" em nome de qualquer moral supostamente autorizada pela apropriação de seu controle a partir de qualquer consistência ideológica e/ou imaginária. Sob o mito do eterno e verdadeiro feminino, que não há, não se pode e/ou deve, transformar a ficção em certeza, para, com isto, abolirmos o Ics. Seria a histeria fingindo-se de fetiche...

Em suma, a partir deste tipo de reconsirleração da categoria de memória, empreendida inicialmente pela Psicanálise, a própria História, por incorporar a influência dupla da Psicanálise e da Teoria da Literatura, passa a também ser, positivamente, vista como ficção. E a memória, por se articular, em liame social, com as fantasias imaginárias, deve, principalmente no Brasil, ser crivada pelas agudas e simbólicas lentes das identificações: narcísica, à função paterna e seu traço unário, e histérica, bem como pela reinterpretação ficcional de nossa história cotidiana (Cf. BARBOSA, Marialva-Imprensa, Poder e Público, Niterói, EDUFF, 1996) de modo a que ali se denuncie os novos "senhores da memória", e se faça isto para que se evite a vigência do culto massivo $\mathrm{e}$ fetichista à idolatria perversa, à imaginária e egóica identificação às "personalidade atraentes": os verdadeiros "senhores da mídia". É esta a política do futuro, porque já vigente, principalmente, no Brasil. E, por fim, cabe a pergunta: do que necessariamente devemo-nos lembrar e/ou esquecer, se, no presente, na adoção da "razão cínica", qual outrora, na função perversa do "mito do pudor" vitoriano, o que se fazia era 
dissimular, sobo manto diáfano do império "onde o sol jamais se punha", a maior era das desigualdades até então presenciada? Qual seria disto a nossa versão "pós-moderna"? Seria apenas a adoção do que o psicanalista croata Zizek categorizou como "razão cínica", a dissimular a (agora) permanente confusão entre desigualdade e diferença como um racista e eficaz álibi da retórica da exclusão? E se isto fosse não apenas uma ideologia sócio-liberal, mas um imperativo da globalização econômico-cultural, como insistir nesse fato, diante tanto da simulação imperial do orgulho (como se fosse mestria), quanto da cotidiana tragédia histórica diante de uma insistente e repetitiva incompletude do presente? E como somos ibéricos só nos resta cantar da Mensagem pessoana a única memória possível: as saudades do Futuro.

Nota:

Texto apresentadoem primeira versão no Espaço Cultural Maria Jacinta, em Niterói, $3^{\text {a }}$ feira, dia 07/05/1996, e, em versão definitiva na Mesa sobre: Modalidades e Formas da Crítica Literária, em 26/08/1996, 6 feira, no XXVIII Congresso Brasileiro de Língua e Literatura, realizado no Instituto de Letras da UERJ, sob os auspícios da SBLLe Fundação Calouste Gulbenkian. 